\title{
KEEPING YOUR HEAD ON STRAIGHT: PROTECTING INDIANA YOUTH ATHLETES FROM TRAUMATIC BRAIN INJURIES THROUGH "RETURN-TO- Play" Legislation
}

\author{
Andrew W. Breck*
}

I. INTRODUCTION

II. MEDICAL BACKGROUND.

A. Definition and Symptoms of a Concussion

B. Grades of Concussion.

C. Diagnosis and Testing for Concussions ...............................221

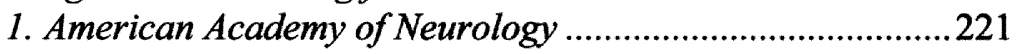

2. ImPACT Testing.

D. Second Impact Syndrome ..................................................223

E. Long-term Health Effects................................................224

III. ACtions BY STATE LEgislatURES to PROTECT YoUTH ATHLETES FROM TRAUMATIC BRAIN INJURY .....................................................225

A. State of Washington's "Lystedt Law"...................................225

$B$. Comparing the Lystedt Law with Variations of

Return-to-Play Legislation Enacted by Other States ..................226

1. Uniform Concussion Guidelines and Distribution

of Education Materials.....................................................227

2. Training Programs........................................................228

3. Informed Consent To Play and Submission of

Medical History ...................................................................229

4. Immediate Removal From Play.......................................230

5. Return-to-Play Requirements........................................2231

6. Neuropsychological Testing...........................................233

IV. CURRENT RETURN-TO-PLAY GUIDELINES IN INDIANA ....................233

V. ANALYSIS OF INDIANA'S CURRENT "RETURN-TO-PLAY” LAW ...........235

A. Indiana's New Law ..........................................................235

1. Uniform Concussion and Head Injury Guidelines...............236

2. Signed Information Sheet and Form ................................236

3. Immediate Removal from Play........................................236

4. Return-to-Play Protocol: Written Clearance from a

Licensed Health Care Provider ..............................................2237

B. Critique of Indiana's Proposed Legislation.............................237

1. Uniform Concussion and Brain Injury Guidelines ..............238

2. Mandatory Concussion and Head Injury Training..............238

3. Personal Brain Injury Information Sheet and Form............240

4. ImPACT Testing...............................................................240

5. Return-to-Play Protocol: Requirements of the Licensed

Health Care Provider, Gradual Return-to-Play, and a 


\section{INTRODUCTION}

Justin Joyce, an Indianapolis-area football player, took a knee to his temple in the first game of the 2010 high school football season. ${ }^{1}$ Joyce felt that something was not quite right, but he continued to play in the game. ${ }^{2}$ Although Joyce finished the game, he reported feeling ill after sustaining the jarring blow to his head. ${ }^{3}$ After taking a minor hit in a game the following week, Joyce lost his balance and was removed from competition. ${ }^{4}$ Joyce was diagnosed with a concussion the next day. ${ }^{5}$

A "concussion is an invisible injury in a lot of cases, [and] therefore there is no awareness of the injury." Although concussions may be invisible to the naked eye, a recent spike in traumatic brain injuries suffered by youth athletes participating in amateur sports has cast a national spotlight on the issue. From 2006 to 2009, a study conducted by the National Center for Catastrophic Sport Injury Research at the University of North Carolina reported that thirty-two high school and youth athletes suffered permanent brain damage and nine died from head injuries. ${ }^{7}$ Even more alarming, the rate of head injuries in youth athletes reported by the Center nearly doubled the total from the previous four years. ${ }^{8}$

The emerging national initiative to combat traumatic brain injuries sustained by youth athletes gained steam following an incident in the state of Washington. In October 2006, Zackery Lystedt, a youth athlete from Tacoma, Washington, complained of pain in his head after making a routine tackle during a junior high school football game. ${ }^{9}$ After minimal inquiry and no medical tests, coaches later allowed Lystedt to return to competition

* J.D. Candidate, 2012, Indiana University Robert H. McKinney School of Law; B.A., 2006, DePauw University.

1. Nat Newell, The Hardest Hit, InDIANAPOLIS STAR, Oct. 1, 2010, § Local - Metro \& State, at $\mathrm{A} 1$.

2. Id.

3. Id.

4. Id.

5. Id.

6. Melissa Healy, Sideline Athletes with Concussions, Group Says, CHI. TRIB., Nov. 2, 2010, § News, at 13 (quoting Dr. Jeffrey Kutcher from the NeuroSport program at the University of Michigan).

7. Newell, supra note 1, at A1.

8. Id.

9. The Zack Lystedt Law: Preventing Brain Injuries in Children, PATIENT POWER (May 14, 2009), http://www.patientpower.info/program/the-zack-lystedt-law-preventingbrain-injuries-in-children/transcript/2. 
after halftime. ${ }^{10}$ Unbeknownst to anyone, Lystedt had suffered a concussion, and toward the end of the game he collapsed into a coma. ${ }^{11}$ Emergency surgery on both sides of Lystedt's brain saved his life, but he suffered considerably following the injury. ${ }^{12}$ Lystedt was unable to speak for nine months and could not move his limbs for thirteen months. ${ }^{13}$ Although he has since regained these functions, Lystedt remains confined to a wheelchair, suffering severe cognitive defects. ${ }^{14}$ More than three years after the injury, Lystedt continues to undergo forty hours of therapy every week in a determined effort to rehabilitate. ${ }^{15}$ In the years following the incident, the Lystedt family along with assistance from the Brain Injury Association of Washington successfully lobbied for passage of the Lystedt Law. ${ }^{16}$ The Lystedt Law is the nation's first state statute requiring adherence to a strict protocol in allowing youth athletes to return-to-play following an apparent brain injury. ${ }^{17}$

Unfortunately, both the Joyce and Lystedt stories are not unique. Youth athletes across the nation are suffering concussions with increased frequency in recent years. ${ }^{18}$ A survey conducted during the 2008-2009 season by the Indianapolis-based National Federation of State High School Associations ("NFHS") ${ }^{19}$ estimates that 140,000 high school athletes, or roughly $1.8 \%$ of the total participants, suffer concussions every year. ${ }^{20}$ The issue is not just limited to football. According to the NFHS study, ice hockey and women's lacrosse rank second and third, respectively, in concussion rates. $^{21}$

The American Academy of Neurology issued a position statement in October 2010 supporting implementation of a general policy aimed at protecting youth athletes from suffering serious brain injuries. ${ }^{22}$ According to

10. Id.

11. Scott Sandsberry, Gray Matter: Attitudes Toward Brain Injuries Changing with More Knowledge, YAKIMA HeRALD-REPUBlIC (Wash.), Oct. 29, 2010, http:// sportsyakima.com/2010/10/gray-matter-attitudes-toward-brain-injuries-changing-with-moreknowledge/.

12. The Zack Lystedt Law: Preventing Brain Injuries in Children, supra note 9.

13. Sandsberry, supra note 11.

14. The Zack Lystedt Law: Preventing Brain Injuries in Children, supra note 9.

15. House Call with Dr. Sanjay Gupta: Concussion Crisis in Football (CNN television broadcast Nov. 27, 2010).

16. Megan Foreman, Sidelined for Safety, ST. LeGISLATURES, June 1, 2010, at 28.

17. Id.

18. Concussion, MEDLINEPLus, http://www.nlm.nih.gov/medlineplus/concussion.html (last visited Sept. 24, 2011).

19. See generally about NFHS, National Federation of State High School Associations, http://www.nfhs.org/Activity3.aspx?id=3260 (last visited Sept. 24, 2011) (describing the function of NFHS as "set[ting] directions for the future by building awareness and support, improving the participation experience, establishing consistent standards and rules for competition, and helping those who oversee high school sports and activities").

20. Newell, supra note 1, at A1.

21. Id.

22. Position Statement on Sports Concussion, AM. ACAD. OF Neurology (Oct. 2010), 
the group, the driving force behind advocating for a safer concussion and head injury policy is that sports now rank second only to motor vehicle accidents as a leading cause of traumatic brain injuries in people aged fifteen to twenty-four. ${ }^{23}$

Congress has recently considered at least two bills that would implement national guidelines for identifying and managing concussions in youth athletes. ${ }^{24}$ However, federal legislation has yet to be enacted, and there appears to be a lack of urgency in passing a federal mandate. In fact, the Concussion Treatment and Care Tools Act ("ConTACT Act") unanimously passed the House of Representatives in September 2010, but the Senate "didn't have much time to finish giving consideration" to the bill before the congressional session concluded, thus allowing the proposed legislation to expire. $^{25}$

In the absence of federal regulation, it is critical to have state statutory guidelines regulating a youth athlete's return to the playing field following an apparent head injury. Several states have enacted specific return-to-play legislation based on Washington State's Lystedt Law; Indiana passed its new law in May 2011, which requires compliance by July $1,2012 .{ }^{26}$

Return-to-play legislation is intended to protect youth athletes from the potential long-term or fatal health effects that accompany head injuries. It takes young people longer to heal from concussions than adults. ${ }^{27}$ 'Kids' bodies are still growing; so are their brains. But while they rebound from sprains and strains more easily than creaky adults, kids get hurt worse by blows to the head and take longer to recover." ${ }^{28}$ In fact, an injury that may take an adult's brain five days to heal could require a younger person's brain ten days or even longer to fully recover. ${ }^{29}$ Furthermore, while youth athletes' bodies are growing, they are not in the physical condition to take hits to the head as readily as older, more developed athletes. According to Chris Nowinski, president of the nonprofit Sports Legacy Institute, "High school players generally have weaker necks than college or professional players .... which causes their heads to absorb a greater amount of force when hit." 30

http://www.aan.com/globals/axon/assets/7913.pdf.

23. Id.

24. Darla Carter, Watch Your Head: Concussions Are Serious, Common Injuries Don't Ignore Them, CouRIER-JourNal (Louisville, Ky.), Sept. 30, 2010, at D1.

25. Jackie Friedman, ConTACT Act Creators Seek National Guidelines, STAR-LEDGER (Newark, N.J.), Feb. 5, 2011, § Sports, at 26 (quoting Rep. Bill Pascrell, a sponsor of the ConTACT Act).

26. See IND. CoDE $\S \S 20-34-7-1$ to -5 (2011).

27. Foreman, supra note 16 , at 28 .

28. Editorial, Adults Must Use Their Heads in Handling Young Athletes' Concussions, FORT WORTH STAR-TELEGRAM, Sept. 6, 2010, available at

http://www.star-telegram.com/2010/09/06/2448068/adults-must-use-their-heads-in.html.

29. Foreman, supra note 16, at 28.

30. Chris Hine, Going to Max Protect: IHSA Has New Concussion Rule, but Some Critics Demand More, CHI. TRIB., Aug. 26, 2010, § Chicago Sports, at 6. 
Part II of this Note will discuss concussions from a medical perspective including a definition and common symptoms of concussion, an explanation of the different grades of concussion, diagnosis and current testing methods for concussions, the dangers of Second Impact Syndrome, and the long-term health effects associated with traumatic brain injuries. Part III will discuss the features of Washington State's Lystedt Law, the first return-to-play statute passed by any state legislature, and will compare it with variations of return-to-play legislation subsequently enacted by other state legislatures. Part IV will discuss Indiana's current concussion protocol along with an analysis of the return-to-play legislation recently passed by the Indiana legislature. Finally, Part V of this Note will critique Indiana's new return-to-play law and set forth recommendations for improvement based on observations of the various permutations of the Lystedt Law passed by other state legislatures.

\section{MEDICAL BACKGROUND}

\section{A. Definition and Symptoms of a Concussion}

There is no universal agreement among scientists and medical practitioners on the precise definition of a concussion. ${ }^{31}$ Generally, though, a concussion can be defined as "a complex pathophysiological process affecting the brain, induced by traumatic biomechanical forces." ${ }^{23}$ The Centers for Disease Control and Prevention ("CDC") categorizes a concussion as a type of traumatic brain injury ("TBI"). ${ }^{33}$ In fact, "[t]he term 'concussion' is often used in the medical literature as a synonym for a mild traumatic brain injury." rect blow to the head, face, neck, or elsewhere on the body with an 'impulsive' force transmitted to the head." 35 However, it does not take a complete loss of consciousness to suffer a concussion. ${ }^{36}$

The CDC categorizes the symptoms of concussions into four main

31. Robert C. Cantu, Posttraumatic Retrograde and Anterograde Amnesia: Pathophysiology and Implications in Grading and Safe Return-to-Play, $36 \mathrm{~J}$. ATHLETIC TraINING 244, 244 (2001), available at http://www.ncbi.nlm.nih.gov/pmc/articles/PMC155413/.

32. Paul McCrory et al., Consensus Statement on Concussion in Sport: The 3rd International Conference on Concussion in Sport Held in Zurich, November 2008, $44 \mathrm{~J}$. ATHLETIC TRAINING 434, 435 (2009), available at $\mathrm{http}: / /$ bjsm.bmj.com/content/43/Suppl_1/ i76.full.pdf.

33. Concussion and Mild TBI, Ctrs. For Disease Control \& Prevention, http://www.cdc.gov/concussion/index.html (last updated Aug. 25, 2010).

34. David S. Kushner, Concussion in Sports: Minimizing the Risk for Complications, 64 AM. FAM. PHYSICIAN 1007, 1008 (2001), available at http://www.aafp.org/afp/2001/0915/ p1007.html.

35. Paul McCrory et al., supra note 32, at 435.

36. Editorial, Adults Must Use Their Heads in Handling Young Athletes' Concussions, supra note 28. 
categories: thinking and remembering; physical; emotional and mood; and sleep disturbance. ${ }^{37}$ An individual suffering from a concussion may have difficulty thinking clearly, concentrating, remembering new information, or may feel slowed down. ${ }^{38}$ Physical symptoms include headache, nausea or vomiting, balance problems, dizziness, fuzzy or blurry vision, sensitivity to noise or light, or feeling tired and lethargic. ${ }^{39}$ Some patients with concussions may also complain of a ringing in their ears. ${ }^{40}$ In more severe cases following a traumatic brain injury, an individual may lose consciousness or suffer the effects of amnesia. ${ }^{41}$ Furthermore, an individual may exhibit signs of emotional distress or behavioral changes and become irritable, sad, nervous, anxious, or more emotional than normal. ${ }^{42}$ Finally, an individual with a concussion may suffer disturbances in sleeping patterns including sleeping more than usual, sleeping less than usual, or experiencing difficulty in falling asleep. ${ }^{43}$

Some symptoms of a concussion may appear immediately after impact, while other symptoms may not be immediately ascertainable until days, or potentially even months, after the injury. ${ }^{44}$ In the minutes and days following a concussive brain injury, brain cells that are not irreversibly destroyed may remain alive but in a distinctly more vulnerable state. ${ }^{45}$

\section{B. Grades of Concussion}

As with the definition of a concussion, there is no universal agreement among scientists and medical practitioners on the grading of concussions. ${ }^{46}$ In the field of sports medicine, however, the value of grading scales for assessing the severity of concussive brain injuries is recognized by medical practitioners. ${ }^{47}$ Medical experts at the American Academy of Neurology categorize concussions into three levels: Grade 1 , Grade 2, and Grade $3 .^{48}$

A Grade 1 concussion is characterized by transient confusion, no loss of consciousness, and concussion symptoms or mental status abnormalities

37. Concussion, Ctrs. For Disease Control \& Prevention, http://www.cdc.gov/ concussion/signs_symptoms.html (last updated Mar. 8, 2010).

38. Id.

39. Id.

40. Concussion, MedlinePlus, supra note 18.

41. Paul McCrory et al., supra note 32, at 435.

42. Concussion, CTRS. FOR DISEASE CONTROL \& PREVENTION, supra note 37.

43. $I d$.

44. Id.

45. Cantu, supra note 31, at 244.

46. Id.

47. See Am. Acad. of Neurology, Practice Parameter: The Management of CONCUSSION IN SPORTS 2 (1997), http://www.aan.com/professionals/practice/guidelines/pda/ Concussion_sports.pdf.

48. Id. at 2-3. 
that resolve in less than fifteen minutes. ${ }^{49}$ This grade of concussion is the most common yet most difficult to recognize because an individual suffers only momentary confusion. ${ }^{50}$ A youth athlete may momentarily be dazed but quickly respond to questioning by coaches or evaluating medical personnel. Youth athletes commonly report feeling "dinged" or getting their "bell rung." 51

A Grade 2 concussion is characterized by transient confusion and no loss of consciousness, but concussion symptoms or mental status abnormalities on examination last longer than fifteen minutes. ${ }^{52}$ A persistent Grade 2 concussion lasting longer than one hour is extremely dangerous and warrants immediate medical observation. ${ }^{53}$ A youth athlete suffering from a Grade 2 concussion may exhibit poor concentration or post-traumatic amnesia over an extended period of time. ${ }^{54}$

A Grade 3 concussion involves any loss of consciousness suffered by a youth athlete-either brief (lasting only a few seconds) or more prolonged (lasting several minutes). ${ }^{55}$ A Grade 3 concussion is the easiest to recognize and warrants immediate medical attention. ${ }^{56}$

\section{Diagnosis and Testing for Concussions}

Initially, diagnosis of the grade of a concussion is difficult. It depends partly on information from the injured individual, who may not be medically trained to identify and communicate critical information regarding the effects of the injury. Robert Cantu, a leading expert on concussive injuries, stated that a "[c]oncussion is often referred to as the silent epidemic . . . . It's not always easy to look at somebody and see if they've suffered a concussion." 57

\section{American Academy of Neurology}

The American Academy of Neurology provides a breakdown for onsite evaluations of concussions, which includes mental status testing, external provocative testing, and neurological testing. ${ }^{58}$ The mental status read-

49. Id.

50. Id. at 3 .

51. Id.

52. Id.

53. Id.

54. Id.

55. Id.

56. Id.

57. Jack McCluskey, Tackling a Silent Epidemic: New Law Aims at Curbing SportRelated Concussions, But Is It Enough?, ESPNBoston.com (Aug. 24, 2010 3:37 PM), http://sports.espn.go.com/boston/news/story?id=5489974.

58. See AM. ACAD. OF NEUROLOGY, supra note 47 at 3. 
ing assesses: (1) orientation, by asking an individual to recite the time, place, person, and situation; (2) concentration, by asking an individual to count backwards or recite a sequence of items in reverse order; and (3) short-term memory, by asking about recent events, either regarding the athletic competition where the injury was sustained or other newsworthy events. $^{59}$

The external provocative test requires the individual to perform an athletic maneuver (e.g., push-ups, sprinting, sit-ups, or knee bends) in order to evaluate any differences in performance from before the injury. ${ }^{60}$ If the youth athlete exhibits abnormal signs, such as headaches, dizziness, nausea, blurred vision, or emotional aberrations, then the sideline medical evaluators will classify the injury as a concussive event. ${ }^{61}$

Finally, the neurological testing for a concussion injury includes examining an individual's: (1) pupils for symmetry and reaction time; (2) coordination, through a finger-nose-finger, in tandem with walking, test; and (3) sensation, through a finger-nose, eyes-closed test. ${ }^{62}$

\section{ImPACT Testing}

A more popular concussion diagnostic tool is called the Immediate Post-Concussion Assessment and Cognitive Testing ("ImPACT"). ${ }^{63}$ Developed in the early 1990's, ImPACT "is the first, most-widely used, and most scientifically validated computerized concussion evaluation system." ImPACT is a twenty-minute evaluation that measures an individual's performance across a number of physical, mental, and neurological criteria including attention span, working memory, sustained and selective attention time, response variability, non-verbal problem solving, and reaction time. ${ }^{65}$ The scores of an individual taken post-injury are compared with baseline testing performed on the athlete prior to the injury in order to detect abnormalities and whether a concussion has occurred. ${ }^{66}$ A popular feature of ImPACT is that it can be conducted by anyone trained to administer the baseline testing including an athletic trainer, school nurse, athletic director, team coach, or team doctor. ${ }^{67}$

ImPACT is administered on a computer and monitored by a qualified

59. See id.

60. See id.

61. See id.

62. See id.

63. About ImPACT: Overview and Features of the ImPACT Test, IMPACTTEST.COM, http://impacttest.com/about/background (last visited July 9, 2011).

64. Id.

65. Id.

66. Id.

67. Id. 
professional trained on the software. ${ }^{68}$ The test is broken down into five separate sections, each compiling a variety of medical data. ${ }^{69}$ Section 1 requires individuals to insert basic demographic information and answer a brief health history questionnaire. ${ }^{70}$ Section 2 then asks questions pertaining to the current concussion symptoms being experienced. ${ }^{71}$ Specifically, this section asks about the date of the most recent concussion, number of hours slept afterward, and current medications taken after the injury. ${ }^{72}$ Additionally, this section requires individuals to rate the severity of twentytwo concussion symptoms, which ultimately factor into the individual's final score. ${ }^{73}$ Section 3 is a neurocognitive test and is split into six separate modules: (1) word discrimination; (2) design memory; (3) "X's and O's," a visual recognition test gauging reaction times to illuminated on-screen objects; (4) symbol matching; (5) color matching; and (6) a three-letter memory task. ${ }^{74}$ Then, Section 4 requires a more detailed description of the concussive event, including details on loss of consciousness, a description of any mouthguard or helmet worn at the time, and the point of contact. ${ }^{75}$ Lastly, Section 5 presents the graphical display of data showing and explaining the individual's overall ImPACT results. ${ }^{76}$ Using the results from the six modules in Section 3 of the test, this section presents a composite of the athlete's final scores relative to verbal memory, visual memory, reaction time, and impulse control. ${ }^{77}$ The final cumulative score then can be used to identify a concussed individual suffering from the effects of a traumatic brain injury from a non-injured individual. ${ }^{78}$

\section{Second Impact Syndrome}

A series of repeated concussions over a short period of time may lead to a serious condition commonly referred to as Second Impact Syndrome

68. $I d$.

69. Id.

70. About ImPACT: Test Features - Questionnaire, IMPACTTEST.COM, http://impact test.com/about/test_features/questionaire (last visited Aug. 10, 2011).

71. About ImPACT: Test Features - Current Symptoms \& Condition, IMPACT TEST.COM, http://impacttest.com/about/test_features/current_symptoms (last visited Aug. 10, 2011).

72. Id.

73. Id.

74. About ImPACT: Test Features - Neurocognitive Test, IMPACTTEST.COM, http:// impacttest.com/about/test features/neurocognitive test (last visited Aug. 10, 2011).

75. About ImPAC $\bar{T}$ : Test Features - Description of the Concussion Injury, IMPACTTEST.COM, http://impacttest.com/index.php/about/test_features/injury_description (last visited Aug. 10, 2011).

76. About ImPACT: Test Features - Graphic Display of Data, IMPACTTEST.COM, $\mathrm{http}: / /$ impacttest.com/index.php/about/test_features/graphic_display (last visited Aug. 10, 2011).

77. Id.

78. Id. 
("SIS"). ${ }^{79}$ SIS develops when an athlete suffers a second head injury before symptoms have fully subsided from the first brain trauma ${ }^{80}$ A second impact that causes SIS need only be a minor blow and may not even be directly to the head, but the blow will cause the individual's head to snap and "impart accelerative forces to the brain." concussion symptoms and the individual will generally appear stunned and exhibit symptoms of a Grade 1 concussion. ${ }^{82}$ Within fifteen seconds to several minutes of the second impact, an individual will collapse with rapidly dilating pupils, loss of eye movement, and respiratory failure. ${ }^{83}$

Studies have shown that the severity and duration of functional impairment may be significantly increased with repeated concussions. ${ }^{84}$ Robert Cantu stated that "[o]nce a player has incurred an initial cerebral concussion, his or her chances of incurring a second one are 3 to 6 times greater than for an athlete who has never sustained a concussion., ${ }^{, 85}$

\section{E. Long-term Health Effects}

Long-term outcomes for individuals suffering concussions and other brain injuries include deficits in memory, reasoning, sensation, language, and emotion. ${ }^{86}$ A Traumatic Brain Injury ("TBI") such as a concussion may also cause significant long-term health effects including epilepsy and an increased risk for Alzheimer's disease, Parkinson's disease, and other brain disorders. ${ }^{87}$ Repeated, mild TBIs occurring over an extended period of time, such as within months or years, can cause cumulative neurological and cognitive defects. ${ }^{88}$ Furthermore, repeated, mild TBIs occurring within a short period of time, such as within hours, days, or weeks, can be catastrophic or even fatal. ${ }^{89}$

79. Kushner, supra note 34 , at 1008.

80. Robert C. Cantu \& Robert Voy, Second Impact Syndrome a Risk in Any Contact Sport, 23 PHYSICIAN \& SPORTSMEDICINE 27 (1995).

81. Id.

82. Id.

83. Id.

84. Cantu, supra note 31 , at 246.

85. Id.

86. Traumatic Brain Injury: Long-Term Outcomes, CTRS. FOR DISEASE CONTROL \& PREVENTION, http://www.cdc.gov/TraumaticBrainInjury/outcomes.html (last visited Mar. 8, 2010).

87. $I d$.

88. Id.

89. Id. 


\section{ACtions By StATE LEgislatures to ProteCt Youth Athletes FROM TRAUMATIC BRAIN INJURY}

\section{A. State of Washington's "Lystedt Law"}

The state legislature of Washington passed the Zackery Lystedt law ("Lystedt Law") in May 2009.90 It was the first state law to implement statutory requirements for youth athletes suffering from concussions." The statute sets forth four key requirements: (1) development of uniform concussion guidelines and distribution of educational materials regarding brain injuries; (2) mandatory consent from parents for participation in youth athletics; (3) immediate removal of the youth athlete from competition after suffering an apparent brain injury; and (4) mandatory compliance with return-to-play protocol before allowing the youth athlete to return to athletic competition. $^{92}$

First, each school district's board of directors must work in concert with Washington's state interscholastic activities associations to develop guidelines on pertinent information regarding concussions. ${ }^{93}$ Then, the collective information must be compiled and communicated to coaches, youth athletes, and parents or guardians of youth athletes. ${ }^{94}$

The educational system established after passage of the Lystedt Law allowed coaches to receive concussion training from online rules clinics, which were offered free of charge from the Washington Interscholastic Activities Association ("WIAA") website. ${ }^{95}$ While coaches are not required to pass an official state examination or obtain state certification as part of the education process, they are responsible for transmitting pertinent information to their youth athletes. ${ }^{96}$ Furthermore, each school district is individually responsible for adopting concussion management policies and ensuring that all coaches receive proper education on the nature, risks, signs, and symptoms of brain injuries prior to the coach's first practice or competition. ${ }^{9}$

Second, on an annual basis, each youth athlete and a parent or guardian must jointly sign and return a concussion and head injury information

90. Foreman, supra note 16 , at 28 .

91. Id.

92. See WASH. ReV. CodE ANN. $\S \S 28$ A.600.190(2) - (4) (West 2011).

93. WASH. REv. CODE ANN. § 28A.600.190(2) (West 2011).

94. Id.

95. Publications: Concussion Management Guidelines - Coaching Resources, WaSH. INTERSCHOLASTIC ACTIVITIES Ass'N, http://www.wiaa.com/subcontent.aspx?SecID=624 (last visited Sept. 24, 2011).

96. Id.

97. Publications: Concussion Management Guidelines - School Resources, WASH. INTERSCHOLASTIC ACTIVITIES ASS'N, http://www.wiaa.com/subcontent.aspx?SecID=627 (last visited Aug. 12, 2011). 
sheet circulated by the school district before the youth athlete is allowed to participate in any sporting practice or competition. ${ }^{98}$ If a youth athlete is suspected of sustaining a concussion or head injury in a practice or game, the youth athlete must be immediately removed from the practice or game at that time. ${ }^{99}$ Moreover, a youth athlete may not be allowed to return-toplay until both of the following criteria are met: the youth athlete is evaluated by a licensed health care provider trained in the evaluation and management of concussions, and the youth athlete receives written clearance to return to play from that licensed health care provider. ${ }^{100}$ The statute allows a volunteer to act as the health care provider for a school district responsible for both the initial concussion evaluation and management, as well as for the subsequent written authorization for the youth athlete to return to competition. $^{101}$

Furthermore, following passage of the Lystedt Law, the WIAA specifically identified which licensed health care providers could conduct the return-to-play protocol: medical doctors, doctors of osteopathy, advanced registered nurse practitioners, physician assistants, and licensed certified athletic trainers. ${ }^{102}$ The WIAA is currently researching other medical providers who may qualify for return-to-play authorization and will communicate any changes directly to all schools in the state. ${ }^{103}$

\section{B. Comparing the Lystedt Law with Variations of Return-to-Play Legisla- tion Enacted by Other States}

Eight other states have since passed specific return-to-play legislation for youth athletics modeled in some part after Washington's Lystedt Law including: Oregon, Oklahoma, Virginia, New Mexico, Connecticut, Rhode Island, Idaho, and New Jersey. Texas previously enacted sport safety laws in 2007 before passage of the Lystedt Law; ${ }^{104}$ however, its requirements are more lenient than the state statutes modeled after the Lystedt Law, focusing only on annual head injury training for coaches and athletic trainers and providing no explicit return-to-play protocol..$^{105}$

98. WASH. REV. CODE ANN. § 28A.600.190(2) (West 2011).

99. WASH. REV. CODE ANN. § 28A.600.190(3) (West 2011).

100. WASH. REV. CODE ANN. § 28A.600.190(4) (West 2011).

101. Id.

102. Publications: Concussion Management Guidelines - Health Care Providers, WASH. INTERSCHOLASTIC ACTIVITIES Ass'N, http://www.wiaa.com/subcontent.aspx?SecID= 628 (last visited Sept. 24, 2011).

103. Id.

104. Editorial, Adults Must Use Their Heads in Handling Young Athletes' Concussions, supra note 28.

105. See Tex. Educ. Code AnN. $\S 33.202$ (West 2011). 


\section{Uniform Concussion Guidelines and Distribution of Education Ma- terials}

Seven states require uniform concussion guidelines to be developed and implemented by local school districts; however, the states differ on the specific collaborative efforts needed to develop the guidelines. In Washington $^{106}$ and Oklahoma ${ }^{107}$ the local school districts work in concert with the states' respective youth interscholastic athletic activities associations to develop concussion guidelines. New Mexico requires the state's activities association and local school districts to develop the guidelines and training programs as well as collaborate with the state's brain injury advisory council. $^{108}$

In contrast, other state statutes require no involvement of local school districts in the guideline development process. For example, the Virginia Board of Education is the sole entity charged with developing concussion guidelines and distributing such guidelines to the local school districts in a top-down directive approach. ${ }^{109}$ In contrast, Rhode Island's statute requires both the state's department of education and department of health to work jointly with the state's interscholastic athletic association to develop the guidelines on concussions and other head injuries. ${ }^{110}$ Idaho also requires collaboration between the state's board of education and the state's high school athletic association. ${ }^{111}$ Idaho provides the most lenient standard and only requires the brain injury guidelines and other pertinent educational forms to be posted and easily retrievable on the state's board of education website ${ }^{112}$ Idaho does not require actual direct distribution of the material to local school districts. ${ }^{113}$

Finally, New Jersey requires its Commissioner of Education to develop a model policy on sports-related concussion guidelines. ${ }^{114}$ This model policy, along with policies established by other organizations specializing in the prevention and treatment of sports-related concussions, ${ }^{115}$ must be reviewed by each school district in developing an individualized written

106. WASH. REV. CODE ANN. § 28A.600.190(2) (West 2011).

107. OKLA. Stat. ANN. tit. 70, $\S 24-155$ (A) (West 2011).

108. N.M. STAT. ANN. § 22-13-31(D) (West 2011).

109. VA. CODE ANN. $\S 22.1-271.5$ (A) (West 2011).

110. R.I. GEN. LAWS ANN. § 16-91-3(a) (West 2011).

111. IDAHO CODE ANN. § 33-1625(1) (West 2011).

112. IDAHO CODE ANN. § 33-1625(2) (West 2011).

113. See id.

114. N.J. STAT. ANN. § 18A:40-41.3(b) (West 2011).

115. N.J. STAT. ANN. $\S 18 A: 40-41.3$ (a) (West 2011) (listing the various organizational policies to consider as "the New Jersey State Interscholastic Athletic Association, the National Collegiate Athletic Association, and the recommendations made by the Brain Injury Association of New Jersey Concussion in Sports Steering Committee, [and] the Athletic Trainers' Society of New Jersey"). 
policy for that district regarding head injuries sustained by youth athletes. ${ }^{116}$ Further, in an effort to ensure availability of the most up-to-date information, each school district's policy must be annually reviewed and updated as necessary. ${ }^{117}$

The current Oregon and Connecticut statutes do not require development of uniform guidelines for concussion management, but they do require development of some form of standardized concussion training. Oregon charges the state's board of education with establishing the appropriate head injury training requirements along with implementing a timeline for completion of this training prior to the start of each athletic season. ${ }^{118}$ Connecticut requires the training guidelines to be developed by the state's board of education in conjunction with the state's intramural and interscholastic activities association, an appropriate organization representing licensed athletic trainers, and an appropriate organization representing county medical associations. $^{119}$

\section{Training Programs}

Several states currently require some form of organized concussion training program. However, the states differ regarding the type of training required, who must participate, and the frequency of training. Oregon's statute is the least stringent and requires only coaches to receive annual training on the recognition of concussion symptoms. ${ }^{120}$ The Oregon statute does not otherwise require any education or organized training program for other school officials, parents or guardians of youth athletes, or the youth athletes themselves. ${ }^{121}$ Connecticut also requires only coaches to complete initial training, but imposes stricter requirements by requiring the coach to review training materials annually and to complete a refresher course every five years. ${ }^{122}$

New Mexico requires each coach participating in school athletic activities to receive training on the nature and risk of brain injury, recognition of symptoms of brain injury, understanding when it is critical to contact medical professionals, and the importance of following medical direction from professionals. ${ }^{123}$ However, the New Mexico statute does not impose a frequency requirement for the training. ${ }^{124}$ The New Mexico statute goes fur-

116. $I d$.

117. $I d$.

118. OR. Rev. Stat. ANN. § 336.485(2) (West 2011).

119. Conn. Gen. Stat. ANN. $\S 10-149$ b(b)(1) (West 2011).

120. OR. REV. STAT. ANN. § 336.485(2)(a) (West 2011).

121. See id.

122. Conn. Gen. Stat. AnN. $\S \S 10-149 \mathrm{~b}(\mathrm{a})(2)-(3)$ (West 2011).

123. N.M. STAT. ANN. §§ 22-13-31(C) - (D)(1) (West 2011).

124. See N.M. STAT. ANN. § 22-13-31 (West 2011). 
ther than the Oregon statute by mandating that the state's athletic activities association develop and distribute educational materials on brain injuries to a wider cross-section of individuals, including coaches, student athletes, and parents or guardians of student athletes. ${ }^{125}$

Rhode Island requires schools to make use of specified training materials made available by the Centers for Disease Control and Prevention ("CDC"). ${ }^{126}$ Rhode Island's Department of Education must post the training materials on its website, making the information readily available to each school district. ${ }^{127}$ Additionally, the Rhode Island statute requires all coaches and volunteers involved in youth athletic activities subject to the state's athletic association to complete a training course on concussions and traumatic brain injuries. ${ }^{128}$ Rhode Island requires the coaches and volunteers to complete a refresher course on an annual basis thereafter. ${ }^{129}$

New Jersey's statute mandates that the state's department of education develop and implement an interscholastic athletic head injury safety training program. ${ }^{130}$ The statute requires school physicians, any coach of a public or nonpublic school interscholastic sport, and all athletic trainers of public and nonpublic school interscholastic programs to complete such training. ${ }^{131}$ Furthermore, the New Jersey Department of Education is required to update the training program when necessary to ensure the appropriate education is provided to the proper individuals. ${ }^{132}$

The Texas statute requires coaches, trainers, and sponsors for extracurricular athletic activities to satisfactorily complete a safety-training program, ${ }^{133}$ which includes certification requirements of all participants from the American Red Cross, American Heart Association, or a similar organization under the state's youth interscholastic athletic association. ${ }^{134}$ Information that must be presented within the training and later provided to student athletes includes recognizing symptoms of catastrophic injuries specifically related to the head and neck, concussions, and Second Impact Syndrome. ${ }^{135}$

\section{Informed Consent To Play and Submission of Medical History}

A majority of states require some form of informed consent or sub-

125. N.M. STAT. ANN. § 22-13-31(D)(2) (West 2011).

126. R.I. GEN. LAWS ANN. § 16-91-3(b) (West 2011).

127. Id.

128. $I d$.

129. $I d$.

130. N.J. STAT. ANN. § 18A:40-41.2(a) (West 2011).

131. Id.

132. N.J. STAT. ANN. § 18A:40-41.2(b) (West 2011).

133. Tex. EdUC. CodE ANN. $\S 33.202$ (b)(1)(West 2011).

134. Tex. Educ. CodE ANN. $\$ 33.202$ (c)(1)(West 2011).

135. TEX. EdUC. CODE ANN. $\S \S 33.202$ (c)(2)(D), (d)(1)(West 2011). 
mission of medical history prior to allowing a youth athlete to participate in sporting activities. Currently, the return-to-play laws require only a youth athlete and the athlete's parent or guardian to annually sign a generic head or brain injury information form developed by either the state or the local school district. Five states require signature of these basic informational forms: Washington, ${ }^{136}$ Virginia, ${ }^{137}$ Oklahoma,${ }^{138}$ New Mexico, ${ }^{139}$ and New Jersey ${ }^{140}$ Rhode Island's statute is even more stringent, requiring the general concussion and brain injury information form to be signed and returned prior to the start of every sport season, which requires a multi-sport athlete and their parent or guardian to sign and return the form before the start of each separate sport season. ${ }^{141}$

Specifically, these general concussion and brain injury information forms communicate the symptoms, risks, and long-term health effects relative to head injuries and are required to be signed and returned to the school or coaches prior to the athletic season to document receipt of the information. Therefore, none of the current return-to-play statutes mandate that a youth athlete provide any personal head injury or concussion history information either to the coaches or to any school district officials prior to participation in athletic competition.

\section{Immediate Removal From Play}

A critical piece of all return-to-play legislation involves the immediate removal of a youth athlete suffering from an apparent head injury from the field of play. Several states currently require an athlete to be immediately removed from practice or competition if they appear to have suffered a head injury or concussion. These states include Washington, ${ }^{142}$ Oregon, ${ }^{143}$ Virginia, ${ }^{144}$ Oklahoma, ${ }^{145}$ New Mexico, ${ }^{146}$ Connecticut, ${ }^{147}$ New Jersey, ${ }^{148}$ and Rhode Island. ${ }^{149}$ These eight states take a more stringent approach to youth athlete head injuries, in that a youth athlete will be immediately removed from play after a head injury, even if the athlete does not suffer unconsciousness. By contrast, the current Idaho laws do not address or require

136. WASH. ReV. CODE ANN. § 28A.600.190(2) (West 2011).

137. VA. CODE ANN. § 22.1-271.5(B)(1) (West 2011).

138. OKLA. Stat. ANN. tit. 70, § 24-155(A) (West 2011).

139. N.M. STAT. ANN. § 22-13-31(E) (West 2011).

140. N.J. STAT. ANN. § 18A:40-41.2(c) (West 2011).

141. R.I. GEN. LAWS ANN. § 16-91-3(c) (West 2011).

142. WASH. ReV. CODE ANN. § 28A.600.190(3) (West 2011).

143. OR. REV. STAT. ANN. § 336.485(3)(a) (West 2011).

144. VA. CODE ANN. § 22.1-271.5(B)(2) (West 2011).

145. OKLA. Stat. ANN. tit. 70, § 24-155(B) (West 2011).

146. N.M. Stat. ANN. $\S \S 22-13-31$ (A)(1)-(2) (West 2011).

147. ConN. Gen. Stat. ANN. $\$ \S 10-149$ c(a)(1)(A)-(B) (West 2011).

148. N.J. STAT. ANN. § 18A:40-41.4 (West 2011).

149. R.I. GEN. LAWS ANN. § 16-91-3(d) (West 2011). 
immediate removal of a youth athlete when he or she appears to have suffered either a head injury or concussion. ${ }^{150}$

\section{Return-to-Play Requirements}

Several states require a youth athlete who appears to have suffered a head injury or concussion to be evaluated before returning to athletic practice or competition. The Rhode Island statute exhibits the least restrictive language by requiring an evaluation from a licensed physician and written clearance before the youth athlete may return to play. ${ }^{151}$ The New Mexico statute is virtually the same and mandates medical clearance by a licensed health care provider. ${ }^{152}$ Oregon's statutory language is similarly broad, requiring the youth athlete to be evaluated and medically released by a health care professional. ${ }^{153}$ These three statutes do not explicitly mandate that the licensed medical personnel who are evaluating and medically clearing the youth athlete have any specific training in concussion or head injury management.

Other state statutes are more strict and require youth athletes suspected of sustaining a head injury to be evaluated by a licensed medical health care provider specifically trained in concussion evaluation and management and receive written clearance from that licensed health care provider prior to returning to competition. These states include Washington, ${ }^{154}$ Oklahoma, ${ }^{155}$ Connecticut, ${ }^{156}$ and New Jersey. ${ }^{157}$ These additional requirements ensure that the medical evaluator has specific training in concussion management and provide a safeguard to ensuring appropriate medical decisionmaking.

Two states provide even more demanding requirements, such as explicitly identifying the medical licenses appropriate to evaluate and manage concussions of youth athletes under return-to-play protocols. New Mexico's statute clearly mandates that the health care professional conducting the return-to-play protocol meet one of the following state licensing requirements: practicing physician or physician assistant licensed under the state's Medical Practice Act, practicing osteopathic physician, practicing certified nurse practitioner, practicing osteopathic physician's assistant, practicing psychologist, or practicing athletic trainer. ${ }^{158}$ Connecticut's statute also mandates that the health care professional meet one of the follow-

150. See IDAHo CodE ANN. § 33-1625 (West 2011).

151. R.I. GEN. LAWS ANN. § 16-91-3(e) (West 2011).

152. N.M. STAT. ANN. $§ 22-13-31$ (B)(2) (West 2011).

153. OR. ReV. StAT. ANN. $\$ 336.485(3)$ (b)(B) (West 2011).

154. WASH. REV. CODE ANN. $\S 28 A .600 .190(4)$ (West 2011).

155. OKLA. STAT. ANN. tit. 70, \& 24-155(C) (West 2011).

156. CONN. GEN. STAT. ANN. $\$ \S 10-149$ c(a)(2), (a)(3)(B) (West 2011 ).

157. N.J. STAT. ANN. $§ 18 A: 40-41.4$ (West 2011).

158. N.M. STAT. ANN. $\S 22-13-31(F)(5)$ (West 2011). 
ing state statutory licensing requirements: licensed physician, licensed physician assistant, licensed advanced practice registered nurse, or a licensed athletic trainer. ${ }^{159}$

Virginia's return-to-play law requires a youth athlete who appears to have suffered a head injury or concussion to be evaluated by a licensed health care provider and receive written clearance from that health care provider prior to returning to competition. ${ }^{160}$ However, the statute also requires that the licensed health care provider be deemed "appropriate," as determined by the state's board of education. ${ }^{161}$ This language provides flexibility in allowing the state board of education to determine the proper medical credentials necessary to perform concussion evaluation and management in youth athletics without providing an exhaustive listing of licensing requirements within the statute itself.

Additionally, Washington, ${ }^{162}$ Virginia,${ }^{163}$ and Oklahoma, ${ }^{164}$ all explicitly allow volunteers to be the licensed medical health care providers responsible for evaluating and authorizing the youth athlete to return to play. By allowing volunteers, these state statutes provide an element of flexibility for school districts to fully comply with return-to-play legislation in a more cost-effective manner.

In addition to regulating the requirements of health care providers performing return-to-play protocol, some state statutes impose a mandatory waiting period before allowing a youth athlete to return to sporting competition. Specifically, Oregon requires a youth athlete to sit out at least one day after the injury before returning to athletic competition. ${ }^{165}$ Even more precautionary, New Mexico does not allow a youth athlete to return to competition for at least one week after sustaining a brain injury. ${ }^{166}$

Connecticut's statute is unique in incorporating a two-tiered approach in its return-to-play protocol. Initially, a youth athlete may be granted written medical clearance from a licensed health care professional to engage in supervised physical exertion. ${ }^{167}$ Following initial clearance from the licensed health care professional to engage in restricted and supervised physical exertion, a youth athlete must receive a second written clearance from that licensed health care professional in order to fully participate in athletic competition without any limitations on contact and physical exertion. ${ }^{168}$ Accordingly, Connecticut requires that coaches gradually introduce the

159. CONN. GEN. STAT. ANN. $\S 10-149$ c(c) (West 2011).

160. VA. CODE ANN. § 22.1-271.5(B)(2) (West 2011).

161. Id.

162. WASH. REV. CODE ANN. § 28A.600.190(4) (West 2011).

163. VA. CODE ANN. § 22.1-271.5(B)(2) (West 2011).

164. OKLA. STAT. ANN. tit. 70, $\$ 24-155$ (C) (West 2011).

165. OR. Rev. StAT. ANN. $\S \S 336.485(3)$ (a)-(b) (West 2011).

166. N.M. STAT. ANN. § 22-13-31(B) (West 2011).

167. ConN. Gen. Stat. ANN. \$ 10-149c(a)(2) (West 2011).

168. Conn. Gen. Stat. ANN. \& 10-149c(a)(3) (West 2011). 
youth athlete back into athletic activity by mandating an initial limitation on physical exertion and continually monitoring the athlete's increased exposure to physical contact and exertion over time.

\section{Neuropsychological Testing}

Rhode Island's statute also encourages, but does not mandate, that schools perform baseline neuropsychological testing on student athletes to aide in concussion management. ${ }^{169}$ No other state's return-to-play protocol explicitly mandates or encourages any specific form of brain testing to be conducted in the evaluation and management of concussions in youth athletes.

\section{CURRENT RETURN-TO-PLAY GUIDELINES IN INDIANA}

Return-to-play legislation was introduced in the Indiana Senate on January 5, 2011, and was passed by both houses in April 2011. ${ }^{170}$ The governor signed the bill on May 10, 2011, and it became effective July 1 , 2011. ${ }^{171}$ The Indiana High School Athletic Association ("IHSAA") is the primary authority for return-to-play issues within Indiana's youth interscholastic athletics until mandatory compliance of this law becomes effective during the 2012-2013 high school athletic season, at which time, regulating return-to-play will be the state's responsibility.

The IHSAA requires member institutions to follow the concussion guidelines promulgated by the National Federation of State High School Associations ("NFHS"). ${ }^{172}$ The current IHSAA protocol requires all member school districts to immediately remove a player from a contest who exhibits signs, symptoms, or behaviors consistent with a concussion, including loss of consciousness, headache, dizziness, confusion, or balance problems. ${ }^{173}$ Under the new Indiana law, the statutory language is more specific than the IHSAA protocol. Currently, the IHSAA protocol requires immediate removal only if the injury occurs during an athletic "contest."."174 Indiana's new law extends the requirement to include removal of a youth

169. R.I. GEN. LAWS ANN. § 16-91-3(c) (West 2011).

170. Action List: Senate Bill 0093, INDIANA GENERAL AsSEMBLY, http://www.in.gov/ apps/lsa/session/billwatch/billinfo?year $=2011$ \&request $=$ getActions\&doctype $=S B \& d o c n o=0$ 093 (last visited July 11, 2011).

171. Id.

172. Newell, supra note 1, at A1.

173. Quick Resources: Concussion Protocol, IHSAA Protocol for Implementation of National Federation of State High School Associations (NFHS) Sports Playing Rules for Concussions, IHSAA.oRG, http://www.ihsaa.org/dnn/Home/tabid/38/Default.aspx (last visited Mar. 10, 2011).

174. Id. 
athlete from the playing field during a practice as well. ${ }^{175}$

Additionally, the current IHSAA protocol requires a youth athlete to be cleared by a "designated health care professional" before returning to competition. ${ }^{176}$ More specifically, the protocol requires game officials who observe a player suffering from an apparent concussion to inform coaches and to advise that the player be removed from competition to be evaluated by the school's designated health care professional. ${ }^{177}$ Under the new Indiana law, the responsibility of removing the youth athlete from competition for medical evaluation is not specifically designated to game officials and, therefore, this responsibility would be more evenly spread among both coaches and game officials alike. ${ }^{178}$

The IHSAA protocol clearly defines a "designated health care provider" who may perform the initial screening of a youth athlete removed from competition as any of the following licensed professionals: medical doctor ("MD") or doctor of osteopathic medicine ("DO") who holds an unlimited license to practice medicine in the state of Indiana; or a certified athletic trainer ("ATC/L") licensed in the state of Indiana. ${ }^{179}$ By contrast, the new Indiana law provides less restrictive language by allowing the initial medical evaluation to be performed "by a licensed health care provider trained in the evaluation and management of concussions and head injuries"180 without listing any specific licensing or certification requirements. Indiana's new law provides additional flexibility by allowing the licensed health care provider to be a volunteer health care provider. ${ }^{181}$

According to current IHSAA protocol, if the designated health care provider determines that the youth athlete did not sustain a concussion and clears the athlete for play, then the head coach may advise game officials of the athlete's medical clearance from the MD, DO, or ATC/L. ${ }^{182}$ The official may then immediately allow the athlete to return to competition. ${ }^{183}$ In contrast, the new Indiana law does not include any explicit reference as to whether a youth athlete may immediately return to play following removal

175. IND. CODE § 20-34-7-4 (2011).

176. Quick Resources: Concussion Protocol, IHSAA Protocol for Implementation of National Federation of State High School Associations (NFHS) Sports Playing Rules for Concussions, IHSAA.ORG, supra note 173.

177. Id.

178. See IND. CoDE § 20-34-7-4 (2011).

179. Quick Resources: Concussion Protocol, IHSAA Protocol for Implementation of National Federation of State High School Associations (NFHS) Sports Playing Rules for Concussions, IHSAA.ORG, supra note 173.

180. IND. CODE § 20-34-7-5(a)(1) (2011).

181. IND. CODE § 20-34-7-5(b) (2011).

182. Quick Resources: Concussion Protocol, IHSAA Protocol for Implementation of National Federation of State High School Associations (NFHS) Sports Playing Rules for Concussions, IHSAA.ORG, supra note 173.

183. $I d$. 
and a subsequent negative initial diagnosis for concussion or head injury. ${ }^{184}$

If the designated health care provider does not authorize the youth athlete to return to competition, then the IHSAA protocol mandates the following requirements be satisfied before the youth athlete may return to play: (1) only a MD or DO may clear the individual to return to competition; (2) the medical clearance must be in writing; and (3) the medical clearance may not be on the same date on which the athlete was removed from play. ${ }^{185}$ Therefore, if the youth athlete is initially diagnosed as exhibiting signs of a concussion or brain injury, an ATC/L cannot authorize the subsequent medical clearance for the youth athlete to return to play. ${ }^{186}$

On the other hand, the new Indiana law provides a less strict protocol. In the event a youth athlete is diagnosed with an apparent concussion or brain injury, the licensed health care provider must still provide written clearance for the youth athlete to return-to-play; ${ }^{187}$ however, there is no explicit requirement for a mandatory sit-out period.

Under the current IHSAA protocol, the official who decided to remove the youth athlete from competition must file a report of the incident with the local school district's athletic director. ${ }^{188}$ The official must file this report regardless of whether the athlete is allowed to return-to-play following removal. ${ }^{189}$ Furthermore, the school's athletic director is then required to file the report and make it available to the IHSAA website. ${ }^{190}$ The new Indiana law requires no formal documentation of the incident to be prepared or retained on file. ${ }^{191}$

\section{ANALYSIS OF INDIANA'S CURRENT "RETURN-TO-PLAY" LAW}

\section{A. Indiana's New Law}

On January 5, 2011, return-to-play legislation was first introduced on the floor of the Indiana Senate by Senator Travis Holdman. ${ }^{192}$ The Senator consulted with the IHSAA, NFL, American College of Sports Medicine, USA Football, and a neurodevelopmental pediatrician at Riley Hospital for

184. See IND. CoDE § 20-34-7-5 (2011).

185. Quick Resources: Concussion Protocol, IHSAA Protocol for Implementation of National Federation of State High School Associations (NFHS) Sports Playing Rules for Concussions, IHSAA.ORG, supra note 173.

186. Id.

187. IND. CODE § 20-34-7-5 (2011).

188. Quick Resources: Concussion Protocol, IHSAA Protocol for Implementation of National Federation of State High School Associations (NFHS) Sports Playing Rules for Concussions, IHSAA.oRG, supra note 173.

189. Id.

190. Id.

191. See IND. CODE $§ 20-34-7-5$ (2011).

192. Action List: Senate Bill 0093, INDIANA GENERAL ASSEMBLY, supra note 170. 
Children in Indianapolis, Indiana prior to introducing the legislation. ${ }^{193}$ The new return-to-play statute is based on requirements already in place under IHSAA rules.

The new return-to-play statute will require the following: (1) development and communication of uniform concussion and head injury guidelines; (2) submission and retrieval of signed head injury information sheets; (3) immediate removal of a youth athlete from athletic competition after sustaining an apparent concussion or head injury; and (4) satisfaction of specific return-to-play protocol before allowing a youth athlete to participate again in athletic competition. Each requirement is discussed in detail below.

\section{Uniform Concussion and Head Injury Guidelines}

First, the new Indiana law requires the Indiana Department of Education to consult with the state's interscholastic athletic association to develop guidelines, information sheets, and forms on the nature and risk of concussions and head injuries. ${ }^{194}$ Next, the Department of Education must disseminate the information to the schools for distribution to coaches, student athletes, and parents of student athletes. ${ }^{195}$

\section{Signed Information Sheet and Form}

The new law further requires that prior to beginning practice for each interscholastic or intramural sport, a concussion and head injury information sheet and form must be given to the student athlete and the athlete's parent. $^{196}$ The information sheet and form is to be developed by the Department of Education. ${ }^{197}$ In order to acknowledge and document receipt of the educational material, both the student athlete and the athlete's parent must sign and return the form to the student athlete's coach. ${ }^{198}$ The coach must then maintain the signed forms on file at the school. ${ }^{199}$

\section{Immediate Removal from Play}

The new Indiana law also requires that any student athlete suspected of sustaining a concussion or head injury must be immediately removed

193. Nat Newell, Concussion Bill Would Follow IHSAA's Lead, INDY.COM (Jan. 5, 2011), http://www.indy.com/posts/concussion-bill-would-follow-ihsaa-s-lead.

194. IND. CODE § 20-34-7-2(a) (2011).

195. Id.

196. IND. CODE § 20-34-7-3(1) (2011).

197. Id.

198. IND. CODE § 20-34-7-3(2) (2011).

199. IND. CODE $\S 20-34-7-3(2011)$. 
from the practice or game at the time of the injury. ${ }^{200}$ Furthermore, the youth athlete is not allowed to return to athletic competition until the specified return-to-play protocol is satisfied. ${ }^{201}$

\section{Return-to-Play Protocol: Written Clearance from a Licensed Health Care Provider}

If a student athlete is removed from practice or competition, the new law then requires the youth athlete to be evaluated by a licensed health care provider trained in the evaluation of concussions and head injuries. ${ }^{202}$ The student athlete will not be allowed to return to athletic competition until receiving written medical clearance from the same licensed health care provider who evaluated the student athlete immediately following the injury. ${ }^{203}$ Finally, the new law allows a licensed health care provider to volunteer his or her services for both the initial evaluation of the youth athlete and the subsequent medical clearance of the youth athlete prior to returning to competition. ${ }^{204}$

\section{B. Critique of Indiana's Proposed Legislation}

Although the proposed return-to-play legislation in Indiana covers the basic concussion and head injury issues for youth athletes enacted in other states, it misses the mark in terms of necessary safety precautions. The legislation is almost directly modeled after the original Washington statute, ${ }^{205}$ but suffers from the same ailments as its Washington forebear. Namely, critics argue the Washington legislation is too weak, stating that " $[t]$ he Lystedt Law, and other state legislation like it, still allows for mismanagement of injuries." 206 Therefore, the following recommendations would succeed in bolstering the Indiana return-to-play legislation, in both providing the necessary protection for youth athletes and establishing Indiana at the forefront of increased safety standards regarding concussion and head injury management in youth athletics.

200. IND. CODE § 20-34-7-4(1) (2011).

201. IND. CODE $\S 20-34-7-4(2)$ (2011).

202. IND. CODE $§ 20-34-7-5(a)(1)(2011)$.

203. IND. CODE \& 20-34-7-5(a)(2) (2011).

204. IND. CODE $\S 20-34-7-5(b)$ (2011).

205. Compare WASH. REV. CODE ANN. $\S \S 28 A .600 .190(2)-(4)$ (West 2011), with IND. CODE $\S \S 20-34-7-1-20-34-7-5$ (showing similarity in the statutory language employed with only minor differences noted in terms of organization of the statutory requirements).

206. Alan Schwarz, Despite Law, Town Finds Concussion Dangers Lurk, N.Y. TrMes, Sept. 23, 2010, at B15. 


\section{Uniform Concussion and Brain Injury Guidelines}

The new Indiana law requires the Department of Education to develop and disseminate the concussion and head injury guidelines with only the assistance of the IHSAA and merely suggests consultation with outside medical professionals. ${ }^{207}$ The new Indiana law should further address involvement in the development process of uniform guidelines. Specifically, the law should mandate that representatives from local school districts work in concert with both Indiana's Department of Education and the IHSAA to develop standard guidelines. Additionally, the law should require that input and research be obtained from other sources with specialized knowledge of concussion and head injury treatment and management including local medical professionals. The key to the uniform guidelines' success will lie in adopting rules that adequately protect youth athletes but also allow school districts with limited financial resources the ability to comply. By requiring Indiana's Department of Education, the IHSAA, local school districts, and state medical professionals to collaborate, all voices will be heard and the appropriate provisions can be determined with all parties representing their unique positions.

A second recommendation is to mandate rather than suggest that the guidelines be readily accessible from the IHSAA's website, similar to the Idaho statutory mandate that requires information be posted on the state board of education website. ${ }^{208}$ Additionally, legislation should require an annual review of the uniform concussion and head injury guidelines by the IHSAA and Department of Education, similar to New Jersey's statutory

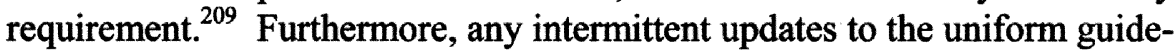
lines that occur during the year should be communicated from the IHSAA directly to local school districts when appropriate to provide the most updated safety information.

\section{Mandatory Concussion and Head Injury Training}

Indiana's new return-to-play law does not currently mandate any formal educational training on concussion and head injury evaluation and management. The language in the new law only requires information on the nature and risk of concussion be "disseminated" by Indiana's Department of Education. ${ }^{210}$ This language is simply not strong enough to effect a proper mandate of concussion and head injury education to youth athletes and coaches.

207. IND. CODE §§ 20-34-7-2(a) - (b) (2011).

208. Compare IND. CODE $\S 20-34-7-2$ (c) (2011) with IDAHO CODE ANN. $\S 33-1625(2)$ (West 2011).

209. N.J. STAT. ANN. § 18A:40-41.3(a) (West 2011).

210. IND. CODE $\S \S 20-34-7-2$ (a) (2011). 
Prior to the beginning of each athletic season, Indiana's law should include mandatory training for all coaches and youth athletes subject to Indiana's interscholastic athletic association. The American Academy of Pediatrics' Council on Sports Medicine and Fitness purports that "[r]ecognition and education are paramount, because although proper equipment, sport technique and adherence to rules . . . may decrease the incidence or severity of concussions, nothing has been shown to prevent them."211

Awareness of the signs and symptoms of concussions is critical to proper head injury evaluation and management. Without proper education, youth athletes are not in the best position to recognize symptoms of concussions and head injuries and to adequately protect themselves from potential long-term negative health effects. Anonymous questionnaires released to high school football players after the season ended yielded information that $15 \%$ of athletes admitted to sustaining a concussion. ${ }^{212}$ Through the same study, the number increased to about $50 \%$ when the word concussion was omitted and only concussion symptoms were listed. ${ }^{213}$ Furthermore, 35\% of the players reported suffering from two or more incidents of head trauma. 214

Even more troubling is that youth athletes tend to shy away from selfreporting injuries for fear of being perceived as weak by coaches and fellow teammates. ${ }^{215}$ Furthermore, "[m]any athletes fear they will be stigmatized or demoted if they admit to being hurt, so they lie about their condition."216 Therefore, "it is important not only to inform athletes, coaches and parents of the risks of concussion but also to impress upon them the benefits of reporting and recovering from a concussion early on."217

A statute mandating annual concussion training would accomplish the necessary goal of educating coaches and youth athletes about the symptoms and dangers of not properly managing a head injury. The state mandate should provide school districts with a number of ways to train athletes on concussion and head injury awareness in a number of ways in order to better accommodate various school budget constraints. For example, the training could be offered free online via the IHSAA website. The statutory language should not place a heavy administrative burden on individual

211. Editorial, Adults Must Use Their Heads in Handling Young Athletes' Concussions, supra note 28.

212. Alan Schwarz, Silence on Concussions Raises Risks of Injury, N.Y. TIMES, Sept. 15,2007 , at $\mathrm{A} 1$, available at http://www.nytimes.com/2007/09/15/sports/football/ 15concussions.html?_r=1.

213. Id.

214. Id.

215. See id.

216. Rachel Blount, Mayo Clinic Out to Check Sports Concussions, STAR TRIBUNE (Minneapolis, Minn.), Oct. 21, 2010, at 01A.

217. McCluskey, supra note 57. 
school districts to develop any sophisticated training, as it is unlikely that school districts of limited financial means would be able to comply. In short, the goal should be to equip coaches and youth athletes with general awareness of concussion symptoms and to stress the importance of seeking proper medical management if head injury symptoms present themselves during athletic competition.

\section{Personal Brain Injury Information Sheet and Form}

The new Indiana law only requires that the youth athlete and a parent of the youth athlete sign and return an information sheet and form providing general education on concussions and head injuries. ${ }^{218}$ This check-the-box type of requirement does not go far enough in providing proper concussion and head injury care. The statute should require every youth athlete to submit to the school district's athletic department a personal brain injury information form identifying any past history of concussion or other head injuries suffered by the youth athlete. Also, the youth athlete's personal brain injury information form should be signed by both the youth athlete and his or her respective parent or guardian prior to participation in each athletic season. In order to relieve any additional administrative burden, the personal brain injury information could be reported as a section of the informational sheet and form already required under the new law.

The personal brain injury information form should be developed jointly by the IHSAA, Indiana's Department of Health, and Indiana's Department of Education. The form should be reviewed annually along with the uniform concussion guidelines and updated as necessary to provide for the utmost safety of youth athletes. Furthermore, for ease of access and to assist with compliance, the IHSAA should make the personal brain injury information form readily available on its website.

Overall, the cost of filling out the personal brain injury form would be marginal. Moreover, this provision would allow for local school athletic departments, coaches, and designated medical professionals to be aware of critical head injury history. In turn, this knowledge of a youth athlete's personal medical history will provide for better evaluation and management of the athlete in the event of a subsequent head injury.

\section{ImPACT Testing}

Presently, the Indiana law does not require any form of testing to assist in concussion and head injury management. To further enhance proper medical decision-making, the Indiana statute should require athletes from all IHSAA member schools to undergo baseline ImPACT testing by a li- 
censed medical professional trained in concussion management before the start of every athletic season. This regulation would allow all youth athletes to have a uniform testable basis from which a licensed health care provider responsible for concussion evaluation and management could accurately determine the proper course of action if an injury were to occur during the athletic season.

If an injury occurs during a game or practice, Indiana law should require a post-injury ImPACT test to be conducted, and those results should be measured against the youth athlete's baseline score. ImPACT reduces the speculation in determining when a youth athlete is no longer suffering the effects of a brain injury and can return to the field. ${ }^{219}$ "In fact, neurocognitive testing has recently been called the 'cornerstone' of proper concussion management by an international panel of sports medicine experts." 220

Return-to-play legislation is not intended to add an expense to families of youth athletes or local school districts by requiring a potentially costly medical evaluation. The ImPACT test is an inexpensive twenty-minute test that can be conducted by "anyone trained to administer the baseline testing."221 Local school districts may purchase the ImPACT tool on a yearly subscription for $\$ 500$ to $\$ 1,000$ depending on the anticipated number of baseline tests and post-injury tests required. ${ }^{222}$ Furthermore, additional baseline or post-injury ImPACT tests in excess of the purchased package can be bought as needed in incremental costs of two dollars for each baseline test and ten dollars for each post-injury test. ${ }^{223}$

Already, "[a]pproximately two-thirds of the schools in Indiana use ImPACT" according to Dr. Dan Kraft, co-director of the Indiana Sports Concussion Network. ${ }^{224}$ This statistic suggests that only a minority of IHSAA member schools would need to implement baseline and post-injury ImPACT testing to achieve participation by all member schools. Thus, a statutory mandate would be a useful mechanism of ensuring statewide implementation of ImPACT.

\section{Return-to-Play Protocol: Requirements of the Licensed Health} Care Provider, Gradual Return-to-Play, and a Mandatory Waiting Period

A key point of contention in the passage of return-to-play legislation

219. Newell, supra note 1, at A1.

220. About ImPACT: Overview and Features of the ImPACT Test, IMPACTTEST.COM, supra note 63.

221. Id.

222. Purchase: Order Forms - For Academic Institutions, High Schools, Colleges, and Universities, IMPACTTEST.COM, http://impacttest.com/purchase (last visited Aug. 16, 2011).

223. Id.

224. Newell, supra note 1, at A1. 
in other states has been defining the individuals qualified to evaluate and authorize a youth athlete's return to competition. In Pennsylvania, pending legislation requires that return-to-play protocol be conducted "by a licensed or certified health care practitioner whose scope of practice includes the management and evaluation of concussions. ${ }^{, 225}$ Dr. Mike Cordas, former football team physician at Penn State, believes the terminology is dangerously unrestrictive, and he advises that "[y]ou have to have more than a surface knowledge of concussions ... otherwise you're going to hurt somebody." 226

As a result of this criticism, Indiana should clearly define and limit the class of individuals who can perform the initial evaluation and subsequent authorization to return-to-play to only those who specialize in brain injury evaluation and management. The new Indiana law requiring evaluation and clearance by a "licensed health care provider trained in the evaluation and management of concussions and head injuries"227 teeters on the brink of those dangers noted by Dr. Cordas relative to the proposed Pennsylvania statute. The qualifying word "trained" in Indiana's new law provides too loose of a standard to ensure proper brain injury evaluation and injury management. It is imperative to include explicit language in the Indiana statute that clearly identifies the specific medical professionals allowed to perform return-to-play procedures, including a non-exhaustive list of the types of appropriate state-licensed or state-certified medical personnel. Amending the law to include a non-exhaustive list of qualified medical personnel would put the Indiana statute on par with statutes in Connecticut ${ }^{228}$ and New Mexico. ${ }^{229}$

A second recommendation concerning Indiana's proposed return-toplay protocol involves instituting a two-tiered approach to a youth athlete's return to competition similar to the Connecticut statute. ${ }^{230}$ The Connecticut statute focuses on a supervised, gradual introduction to physical exertion. After sustaining a concussion, athletes should not return to play until symptoms have fully subsided, both before and after gradually increasing physical activity. ${ }^{231}$ More specifically, concussion experts advise that athletes "should follow a guided exercise progression for seven days after becoming symptom-free before returning to full participation."232

225. Chuck Finder, PA. House Concussion Bill Draws a Mixed Reaction Congress Also Wrestling with Issue of Brain Injuries, PITTSBURGH POST-GAZETTE, Sept. 30, 2010, at B1.

226. Id.

227. IND. CODE $\S 20-34-7-5$ (a) (2011).

228. CONN. GEN. STAT. ANN. §10-149c(c) (West 2011).

229. N.M. STAT. ANN. § 22-13-31(F)(5) (West 2011).

230. ConN. Gen. STAT. ANN. §§ 10-149c(a)(2)-(3) (West 2011).

231. Schwarz, supra note 206, at B15.

232. Louise Continelli, Sharing Insight on Sports-Related Concussions, BUFfaLo NEwS (N.Y.), Feb. 6, 2011, § Niagara Week, at 1 (quoting Dr. Anthony Surace, director of sports medicine at the University Sports Medicine of Niagara Concussion Clinic). 
The sponsor of Indiana's new law, Senator Travis Holdman, stated that "doctors around the state are still seeing kids go back to sports too early." ${ }^{233}$ Accordingly, the law in Indiana should mandate a youth athlete be first granted an initial written medical clearance from an appropriate licensed health care professional allowing engagement in limited, supervised physical exertion. Following this initial clearance from the appropriate licensed medical professional to re-engage in limited physical activity, a youth athlete should then be required to receive a second written clearance from the same licensed medical professional authorizing full participation in athletic competition. The ability to monitor a youth athlete's recovery through gradual increases in physical exertion will better safeguard the athlete from returning too quickly and decrease the likelihood of sustaining a subsequent and potentially more dangerous medical injury.

Finally, with the difficulty in gauging concussion symptoms and the medical uncertainty regarding concussions and head injuries, it seems the most risk-averse approach would be for the proposed Indiana legislation to be amended to institute a mandatory waiting period even after concussion and head symptoms subside. As Dr. Joseph O'Neil of Riley Hospital in Indianapolis advocates:

The more we have learned about the effects of a concussion on a young brain, the more we are concerned that the brain needs time to rest and heal. ... If we allow the student-athlete to get back into competition or practice too soon it slows down the healing process and also puts the young person at risk for greater injury. $^{234}$

Concussion specialists have recently emphasized the critical need for a rest period even after an athlete is asymptomatic. ${ }^{235}$ Specifically, one concussion expert advised that patients should wait seven to ten days after they become symptom-free before returning to full athletic competition, stating that " $[t]$ here are biochemical changes occurring in the brain that must return to baseline before returning to full participation."236

Therefore, Indiana's new law should be amended to include a mandatory waiting period. The waiting period should be imposed immediately after a youth athlete is removed from competition and is initially deemed to have suffered a concussion or head injury. While Oregon's statute requires

233. Niki Kelly, State Law on Concussions Proposed: Bill Tightens Rules for StudentAthletes Who Get Hurt, JourNal GAZETTE (Ft. Wayne, Ind.), Dec. 30, 2010, at 1C.

234. Id.

235. Continelli, supra note 232, at 1.

236. Id. (quoting Dr. Anthony Surace, Director of Sports Medicine at the University Sports Medicine of Niagara Concussion Clinic). 
a youth athlete to sit out at least one day following injury, ${ }^{237}$ New Mexico's more expansive one-week standard ${ }^{238}$ would provide an even greater opportunity to properly evaluate a youth athlete's progression through recovery. Furthermore, a mandatory one-week waiting period would aid in allowing the youth athlete ample time to be monitored and evaluated through the suggested two-tiered gradual return-to-play protocol described above.

\section{CONCLUSION}

It is without question that the issue of concussions and other head injuries in youth athletes is a major issue nationwide. The U.S. Congress tried to enact federal legislation last year, but failed to do so, citing a lack of time to give the bill full consideration. ${ }^{239}$ In the absence of a federal mandate, a handful of states have either specific return-to-play legislation or general concussion management statutes currently in force. Numerous other states have proposed similar legislation. Although Indiana youth athletic programs tied to the IHSAA already have a protocol in place based on guidelines promulgated by the NFHS, the current measures do not go far enough and would not carry the weight and breadth of protection that a statutory mandate can provide.

Currently, the new Indiana law provides only basic precautions that must be strengthened to eliminate potential inefficiencies and loopholes. A wider circle of minds should be involved in the development of statewide uniform concussion and head injury guidelines. Specifically, representatives from local school districts should be consulted along with other organizations possessing specialized knowledge in the treatment and management of concussion and other head injuries.

Additionally, amending the legislation to include a mandate for a concussion and head injury safety-training program would put coaches, youth athletes, and parents or guardians on notice of the dangers of playing sports with regard to traumatic brain injuries. The recommended improvements to Indiana's current return-to-play legislation described in this Note would also mandate baseline and post-injury ImPACT testing for all school athletic programs, which will provide a uniform and more accurate way to evaluate and manage all youth athletes suffering from potentially dangerous head and brain injuries.

Furthermore, the suggested enhancements to Indiana's new law outlined in this Note would streamline the return-to-play process by clearly defining the specific medical professionals qualified to conduct the youth athlete's initial evaluation and subsequent written authorization to return-to- 
play, establishing a two-tiered return-to-play protocol focusing on a supervised, gradual return to athletic competition and establishing a uniform mandatory waiting period within which to appropriately evaluate a youth athlete's recovery from a concussion or suspected brain injury.

Although a youth athlete may resist being removed from athletic competition due to a suspected concussion or head injury, the state must consider whether the reward of winning a game is really worth the potential longterm health risks of not removing that athlete from play. Zackery Lystedt's family valiantly fought for passage of the first state statutory mandate for concussion and head injury protection and they "know only too well the ramifications of hoping for the best when, in fact, the worst may be just the next hit away." 240 It is imperative for Indiana to amend its current returnto-play law to provide effective yet fiscally manageable requirements in the name of protecting youth athletes from serious harm. As Kathy Malone Sparks, sports medicine services coordinator for Indianapolis Public Schools puts it, "[y]ou only have one brain, and you'll need it later in life."241 
